\title{
Study of Electrical and Magnetic Properties of Praseodymium Samarium Doped Novel Magnesium Ferrite
}

\author{
Vasant Naidu \\ Professor/ ECE \\ Sethu Inst. of Tech, \\ Pulloor - 626115, \\ Tamilnadu, India
}

\author{
C. Balakumar \\ Scholar /ECE \\ Sethu Inst. of Tech, \\ Pulloor - 626115, \\ Tamilnadu, India
}

\author{
S. Gnana Selvan \\ Scholar/ ECE \\ Sethu Inst. of Tech, \\ Pulloor - 626115, \\ Tamilnadu, India
}

\author{
C. Kailasanathan \\ Dept of Mech Engg \\ Sethu Inst. of Tech, \\ Pulloor - 626115, \\ Tamilnadu, India
}

\begin{abstract}
The Praseodymium, Samarium doped novel Magnesium ferrite $\left(\mathrm{Mg} \operatorname{Pr}_{\mathrm{x}} \mathrm{Sm}_{\mathrm{y}} \mathrm{Fe}_{2-\mathrm{x}-\mathrm{y}} \mathrm{O}_{4}\right)$ was prepared by sol gel route and sintered in a microwave furnace. The nano size, structure and composition of Pr and Sm doped Magnesium ferrite ceramics was analyzed by X-ray diffraction and confirmed by SEM monographs. The elemental conformation was done by EDAX. The hysteresis property of this material was conformed through its hysteresis curves. The permeability of this material was calculated by using the magnetic saturation obtained from the hysteresis curves. The electrical measurements have been performed to determine the dielectric constant $\left(\varepsilon_{\mathrm{r}}\right)$, dielectric loss $\left(\varepsilon_{\mathrm{r}}{ }^{\prime}\right)$ and loss tangent in the frequency range of $20 \mathrm{KHz}-20 \mathrm{MHz}$. It is also found that the permittivity of these nano materials is being reduced with the increase in frequency.
\end{abstract}

Keywords: Pr-Sm doped Mg ferrite; Sol gel, Electrical and Magnetic studied Studies

\section{INTRODUCTION}

Ferrites are ferrimagnetic materials that are particularly attractive at microwave frequencies because they do not obey the reciprocity principle, and can control relatively high powers. Ferrites are polycrystalline (and sometimes single crystal) ceramic materials that are typically formed using a high temperature sintering process [1,4]. They exhibit dielectric behavior with high resistivity and low dielectric losses and are widely used in microwave and millimeter wave applications such as inductors, circulators, isolators, phase shifters, switches, tunable resonators and filters [5]. Metallic magnetic alloys are ferromagnetic materials, with very high magnetization compared to ferrites another attractive feature is that they typically have low coercivities, allowing them to be utilized without need of an external magnetic bias field to saturate the sample, meaning that they are self-biased. They are metallic in nature, so have lower resistivity (than ferrites) and suffer from conductive losses such as skin effect and eddy currents. This severely limits their applications to $\mathrm{RF}<1 \mathrm{GHz}$. However, these materials can be deposited using a low temperature RF sputtering process, making them compatible to semiconductor fabrication. A common application of metallic magnetic alloy is RF planar inductors [6,7].

The co-existence of ferro electricity and ferromagnetism and their coupling with elasticity provide an extra degree of freedom in the design of new functional sensors and multistate devices.
Due to its multiferroism, an electric field can induce change in magnetization and an external magnetic field can induce electric polarization. This phenomenon is known as the magneto electric effect (ME) effect and materials exhibiting this effect are called magneto electrics or signets magnets. Further proof of it being ferromagnetic is that it produces a hysteresis loop during ferroelectric characterization. The ability to couple to either the electric or the magnetic polarization allows an additional degree of freedom in device designs.

One of the major drawbacks of $\mathrm{MgFe}_{2} \mathrm{O}_{4}$ material is the leakage current arising out of its non stoichiometry. This is mostly because of the difficulty in obtaining stoichiometric single phase $\mathrm{MgFe}_{2} \mathrm{O}_{4}$ materials. Therefore it allows current to pass through when a high voltage is applied. Attempts to improve the electrical properties have been made by doping it with rare earth elements such as Lanthanum (La), Praseodymium (Pr), Samarium (Sm), Gadolinium (Gd), Terbium ( $\mathrm{Tb})$ and Cerium (Ce), Dysprosium (Dy) etc. The dopant can be at the A site or the $\mathrm{B}$ site. A site being the edges of the perovskite cell and the $\mathrm{B}$ site being the centre of the perovskite cell.

\section{EXPERIMENTAL PROCEDURE}

\subsection{Synthesis Technique:}

The nano sized Magnesium ferrite doped with different concentration of Praseodymium (Pr) and $\operatorname{Samarium}(\mathrm{Sm})$ is prepared by using Magnesium Nitrate (Merck) and ferric(Lobo Chem) and rare earth $\mathrm{Ce}$ (Alfa Aesar), along with citric acid(Merck) in a certain molar ratio of 1:1 and then dissolved in deionized water, here the citric acid helps the homogenous distribution of the metal ions to get segregate from the solutions. Further a required amount of ammonia is added in order to adjust the $\mathrm{pH}$ value to about 7 , since the base catalysts are employed in order to speed up the reaction. The solution is later subjected to a continuous stirring for duration of $24 \mathrm{hrs}$. This as prepared solution is heated to a constant temperature of $135^{\circ} \mathrm{C}$ to condense it into a xerogel [8-9]. After this dehydration process a brown colored dried gel is obtained. The burnt powder is further crushed in agate mortar to obtain the nano sized powder. Further the powder is subjected to sintering in a microwave furnace.

The grain size of the nanoferrite is determined from the prominent peak of XRD using Scherer's equation. Using the knowledge of site preference of the ions and the ionic size data of the respective ions, the cation distribution has been estimated 
theoretically using the formula as proposed [10, 11]. These nano ferrites possess a very well defined local atomic ordering that may be described in terms of a spinel-type structure with $\mathrm{Mg}^{2+}$ and $\mathrm{Fe}^{3+}$ ions which is almost randomly distributed over its tetrahedral and octahedral sites. The new structural information helps to explain the material's unusual magnetic properties [12]. The experimental magnetic moment is calculated from the following formula [13].

$$
\eta=\frac{\left[M_{W} * M_{S}\right]}{5585}
$$

Where $\mathrm{M}_{\mathrm{W}}$ is the molecular weight of the sample and $\mathrm{Ms}$ is the saturation magnetization in $\mathrm{emu} / \mathrm{g}$.

\subsection{XRD and EDX Studies}

The phase composition of fine ferrite powder is carried out using PAN analytical X'pert PRO diffraction meter using $\mathrm{Cu} \mathrm{K}_{\alpha}$ radiation $\left(\lambda=1.54^{\circ} \mathrm{A}\right)$ at $40 \mathrm{KV}$ and $30 \mathrm{~mA}$ with a scanning rate of $0.01 \%$ s and scan speed of $1 \% \mathrm{~min}$ in a $2 \theta$ range of $10-80^{\circ} \mathrm{A}$. The crystallite size is calculated by taking RWHM of the $1,1,1$ peak in XRD and using the Scherrer formula. The energy dispersive studies (EDAX) are done on Genesis EDAX to confirm the presence of chemical composition of the powder and to study the structure of the powdered material and the presence of the elements.

\subsection{SEM Studies}

SEM Micrographs of the nanoferrite powder are recorded using the scanning electron microscope (HITACHI model S-3000H).

\subsection{Magnetic Measurements}

The Magnetic measurements are performed on the commercial vibrating sample magnetometer (VSM) Lakeshore (Model73009). The Magnetic hysteresis loops are measured at the room temperature with maximal applied magnetic fields up to $0.95 \mathrm{~T}$. Magnetic field sweep rate is kept at $5 \mathrm{Oe} / \mathrm{s}$ for all the measurements, so that the measurement of hysteresis loops with maximum field of $0.989 \mathrm{~T}$ is taken from an interval of three hours. The saturation magnetization, coercivity and remanent magnetization are found from hysteresis loop.

\subsection{Electrical Measurements}

The Electrical measurements are performed using the N4L LCR meter. The experimental set up for measuring the dielectric properties in the microwave region consisted of a pallet holder connected to the N4L LCR meter interfacing the computer. The microwave properties of the four samples $\operatorname{Pr}(\mathrm{x}) \operatorname{Sm}(\mathrm{y})$ doped Magnesium ferrite $\mathrm{x}=0.05,0.06,0.07 \mathrm{y}=0.03$ are investigated at the frequency range from $20 \mathrm{KHz}$ to $20 \mathrm{MHz}$. The electrical conduction mechanism can be explained by the electron hopping model of Heikes and Johnston [17].

\subsection{RESULT AND DISCUSSION:}

\subsection{X-RAY DIFFRACTION}

A careful analysis of the XRD patterns helps to determine the respective planes and face centered cubic structure of these ferrites. Well resolved peaks in XRD pattern clearly indicates the single phase and polycrystalline nature of the samples.

Figure 1 shows XRD patterns of the $\mathrm{Mg} \operatorname{Pr}_{\mathrm{x}} \mathrm{Sm}_{\mathrm{y}} \mathrm{Fe}_{2-\mathrm{x}-\mathrm{y}} \mathrm{O}_{4}$ powders. The diffraction patterns and relative intensities of all diffraction peaks are matched well with those of JCPDS card 221086 for $\mathrm{Co}_{0.5} \mathrm{Zn}_{0.5} \mathrm{Fe}_{2} \mathrm{O}_{4}$ and the Ce diffraction peaks are matched well with those of JCPDS card 34-0394. The peaks are appeared at around $18.5^{\circ}, 30.2^{\circ}, 35.6^{\circ}, 37.2^{\circ}$ and $43.0^{\circ}$ for $\mathrm{Co}$ and $\mathrm{Ce}, 53.4^{\circ}$ for $\mathrm{Ce}$ and $57.1^{\circ}, 62.5^{\circ}$ and $73.7^{\circ}$ appeared for Co. These peaks are well indexed to the crystal plane of spinel ferrite (111), (220), (311), (222), (400), (422), (511), (440) and (533), respectively. The diffraction peaks are quite sharp because of the micrometer size of the crystallite. XRD patterns clearly indicate that the pure Lanthanides doped $\mathrm{MgFe}_{2} \mathrm{O}_{4}$ shows the presence of single-phase cubic spinel structure. The X-ray diffraction patterns show that all samples are formed in cubic single spinel phase. No foreign impurity lines are seen. The lattice parameter a $\left(\mathrm{A}^{\mathbf{0}}\right)$ is calculated using Bragg's law.

Where h, k, 1 are the indices of mentioned planes. Lattice constants of all samples that are prepared in investigation are listed in Table 1.The lattice constants of individual phases do not vary much by the inclusion of Pr-Sm and it was found that the porosity and density had shown an increase with increase in $\mathrm{Pr}$ Sm doping concentration.

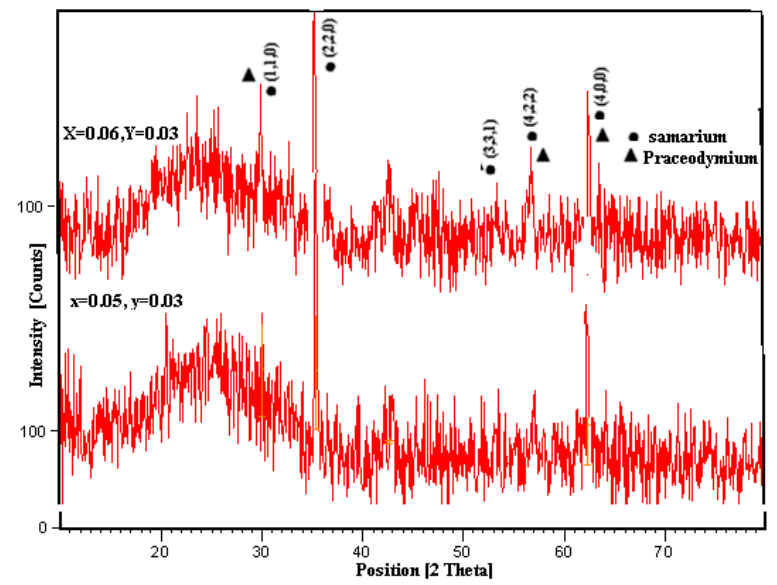

Fig1 XRD patterns of sintered $\mathrm{Mg} \mathrm{Pr}_{\mathrm{x}} \mathrm{Sm}_{\mathrm{y}} \mathrm{Fe}_{2-\mathrm{x}-\mathrm{y}} \mathrm{O}_{4} \mathrm{x}=0.05$ and $\mathrm{y}=0.03$

The size of crystal is evaluated by measuring the FWHM of the most intense peak (311) from XRD and by using the Debye Scherrer's formula [14], the size of the crystal is evaluated.

$$
D=\frac{0.94 \lambda}{\beta \operatorname{Cos} \theta}
$$

Here the XRD patterns exhibit narrow reflection that points out the narrow size crystallites. The mean crystallite size of the sample lies within the range of $41.52 \mathrm{~nm}$ to $54.79 \mathrm{~nm}$. The lattice parameter increased with increasing the doping concentration. 
Table 1 Lattice parameter $(a)$, crystallite size $(D), \mathrm{X}$-ray density $(d x)$, porosity $(p)$ and observed molar contents of $\mathrm{Mg} \mathrm{Pr}_{\mathrm{x}} \mathrm{Sm}_{\mathrm{y}} \mathrm{Fe}_{2}$ $x-y \mathrm{O}_{4}$

\begin{tabular}{|c|c|c|c|c|}
\hline $\begin{array}{c}\mathrm{Zn}_{1-\mathrm{x}-\mathrm{y}} \mathrm{Ce}_{\mathrm{x}} \\
\mathrm{Co}_{\mathrm{y}} \mathrm{Fe}_{2} \mathrm{O}_{4}\end{array}$ & $\begin{array}{c}\mathrm{x}=0.05 \\
\mathrm{y}=0.03\end{array}$ & $\begin{array}{c}\mathrm{x}=0.06 \\
\mathrm{y}=0.03\end{array}$ & $\begin{array}{c}\mathrm{x}=0.08 \\
\mathrm{y}=0.04\end{array}$ & $\begin{array}{c}\mathrm{x}=0.09 \\
\mathrm{y}=0.05\end{array}$ \\
\hline $\mathrm{a}\left(\mathrm{A}^{\circ}\right)$ & 8.145 & 8.196 & 8.23 & 8.36 \\
\hline $\mathrm{D}(\mathrm{nm})$ & 41.52 & 43.62 & 48.21 & 54.79 \\
\hline $\begin{array}{c}\mathrm{d}_{\mathrm{x}} \mathrm{x} 10^{3} \\
\mathrm{gcm}-3\end{array}$ & 3.456 & 3.687 & 3.948 & 4.239 \\
\hline$p$ & 0.321 & 0.315 & 0.304 & 0.298 \\
\hline $\begin{array}{c}\text { Observed } \\
\text { contents } \\
(\mathrm{Pr})\end{array}$ & 0.05 & 0.06 & 0.08 & 0.09 \\
\hline $\begin{array}{c}\text { Observed } \\
\text { Contents } \\
(\mathrm{Sm})\end{array}$ & 0.03 & 0.03 & 0.04 & 0.05 \\
\hline
\end{tabular}

It is also seen that the density of magnesium ferrite increased with the doping concentration of $\mathrm{Pr}^{3+}-\mathrm{Sm}^{2+}$ shown in Fig.3(b), it is because the molecular weight of the Praseodymium (140.902 amu) and Samarium (150.36 amu) are higher than the molecular weight of $\mathrm{Fe}(55.845 \mathrm{amu})$, so when the $\mathrm{Pr}$ and $\mathrm{Sm}$ are replaced by $\mathrm{Fe}$, and therefore the density increases). The percentage of porosity in Dy-Sm doped magnesium ferrite was decreased from 0.321 to 0.298 with respect to the increasing doping concentration

\subsection{EDAX}

The EDAX spectra obtained from the center of Mg substituted $\mathrm{Pr}-\mathrm{Sm}$ ferrite grains indicated the presence of small concentration of $\mathrm{Mg}$ inside the grains Maximum of 567 counts was seen for Fe at $6.3 \mathrm{Kev}$ and 7.0 Kev Whereas for $\mathrm{Mg}$ it was 252 counts at $1.2 \mathrm{Kev}$, Whereas for Samarium it was 239 and 220 having the percentage 5 at $5 \mathrm{Kev}$ to $7 \mathrm{Kev}$, Whereas for Praseodymium it was seen at 4.5 to $6.5 \mathrm{Kev}$.

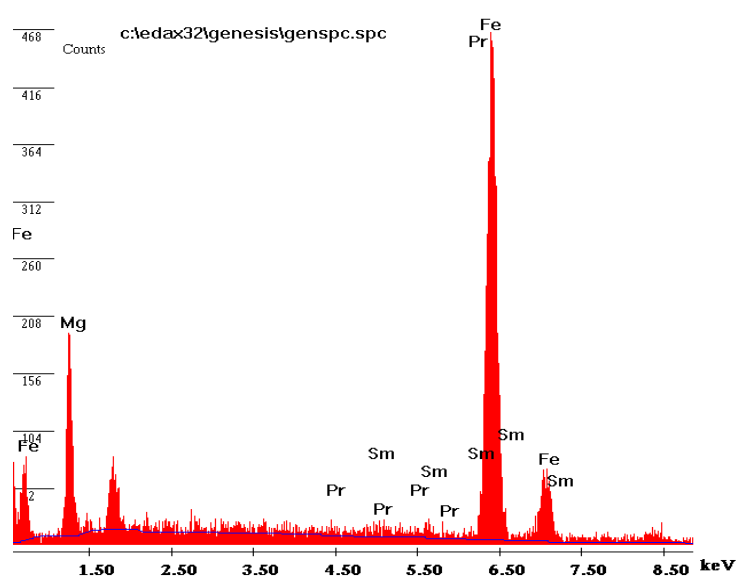

Fig.2 EDAX pattern for $\mathrm{Mg} \mathrm{Pr}_{\mathrm{x}} \mathrm{Sm}_{\mathrm{y}} \mathrm{Fe}_{2-\mathrm{x}-\mathrm{y}} \mathrm{O}_{4}$ $\mathrm{x}=0.05,0.03$

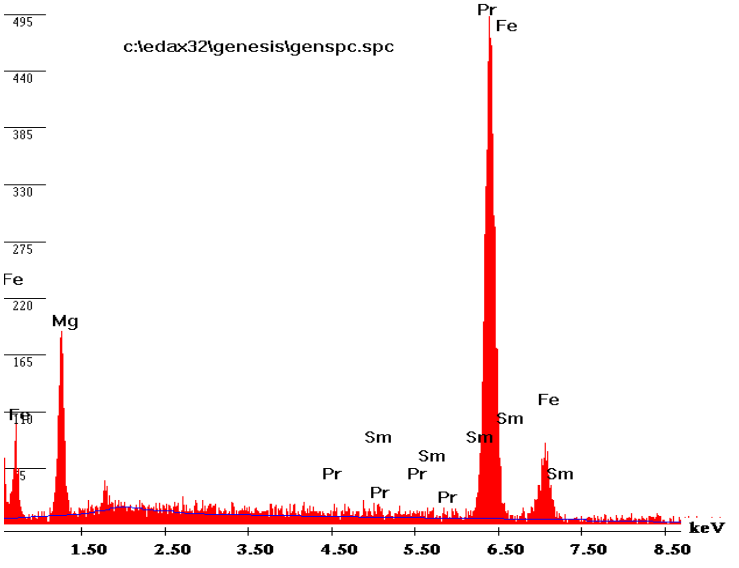

Fig.3 EDAX pattern for $\mathrm{Mg} \mathrm{Pr}_{\mathrm{x}} \mathrm{Sm}_{\mathrm{y}} \mathrm{Fe}_{2-\mathrm{x}-\mathrm{y}} \mathrm{O}_{4} \mathrm{x}=0.06,0.03$

\subsection{SEM analysis}

The nano phase is investigated by using the SEM micrograph, as shown in Fig. they show the microstructure of the sintered specimen. These Ce-doped specimens show a bi-phasic microstructure constituted of dark ferrite matrix grains and small whitish grain at the grain junction/boundary. As proposed by Sattar et, al [15] the rare earth ions occupy either the iron positions or go to the grain boundaries. However, we have to exclude the probability that the rare earth ions occupy the A site of $\mathrm{Fe}^{3+}$ ions. This is due to the fact that the tetrahedral sites are small to be occupied by the large rare earth ions which have large ionic radius.

Of course the probability of occupancy of the octahedral (B-site) is by the rare earth ions (Ce). With the increase in $\mathrm{Ce}$ ions the ionic radius $\mathrm{R}$ decreases. This is indicated by the whitish grains of $\mathrm{Ce}-\mathrm{Co}$ with $\mathrm{Fe}{ }_{2} \mathrm{O}_{4}$. The amount of $\mathrm{Pr}$-Sm with $\mathrm{Fe}_{2} \mathrm{O}_{4}$ is maximum in $\mathrm{x}=0.016$ composition. The grain size of matrix phase is also maximum in $\mathrm{x}=0.016$ composition. Relatively lower grain size of ferrite matrix is seen in $\mathrm{x}=0.012$ compositions, it may be due to the grain growth inhibition caused by $\mathrm{Ce}_{2} \mathrm{Fe}_{2}$. 


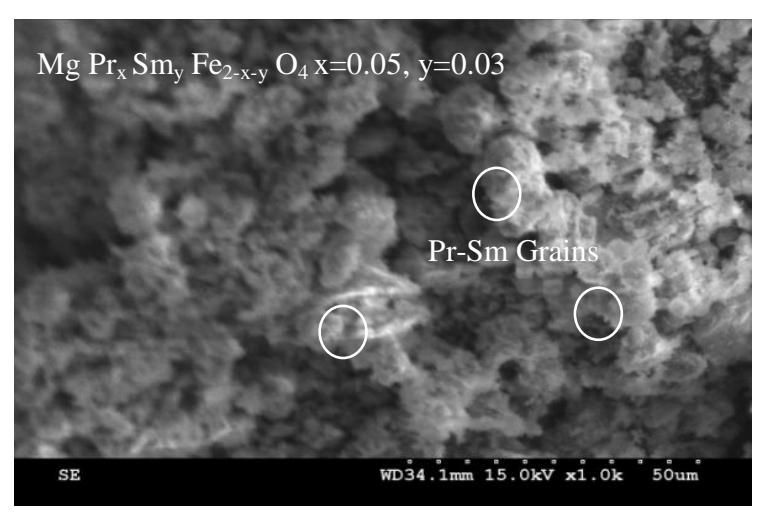

Fig.4 $\mathrm{Zn}_{1-x-y} \mathrm{Ce}_{\mathrm{x}} \mathrm{Co}_{\mathrm{y}} \mathrm{Fe}_{2} \mathrm{O}_{4} \quad \mathrm{x}=0.05, \mathrm{y}=0.03$

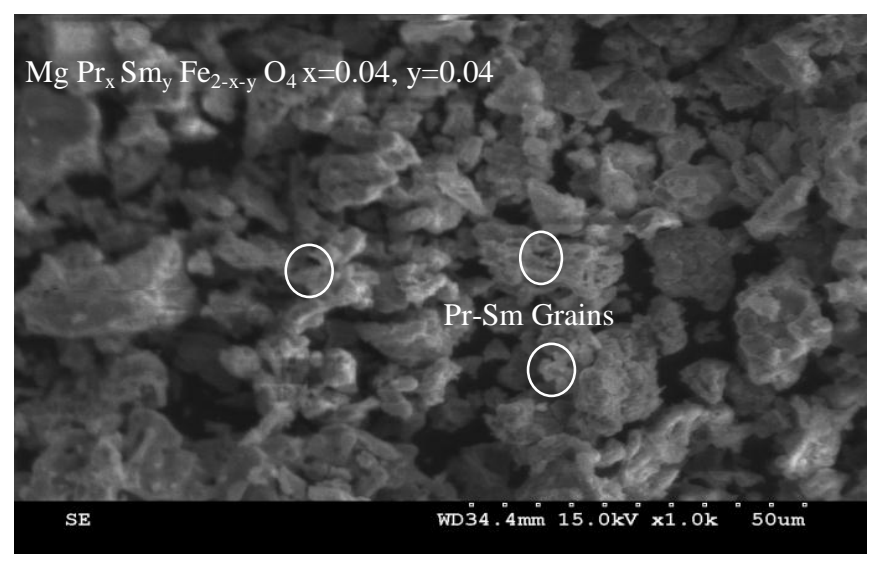

Fig.6 $\mathrm{Mg} \mathrm{Pr}_{\mathrm{x}} \mathrm{Sm}_{\mathrm{y}} \mathrm{Fe}_{2-\mathrm{x}-\mathrm{y}} \mathrm{O}_{4} \mathrm{x}=0.08, \mathrm{y}=0.04$

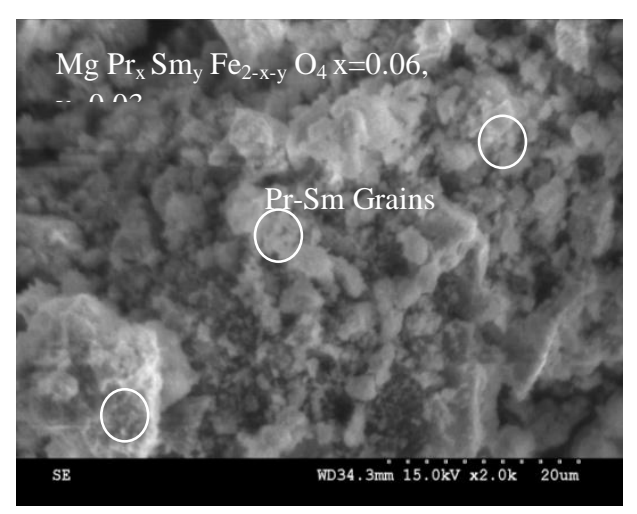

Fig.5 $\mathrm{Zn}_{1-\mathrm{x}-\mathrm{y}} \mathrm{Ce}_{\mathrm{x}} \mathrm{Co}_{\mathrm{y}} \mathrm{Fe}_{2} \mathrm{O}_{4} \mathrm{x}=0.06, \mathrm{y}=0.03$

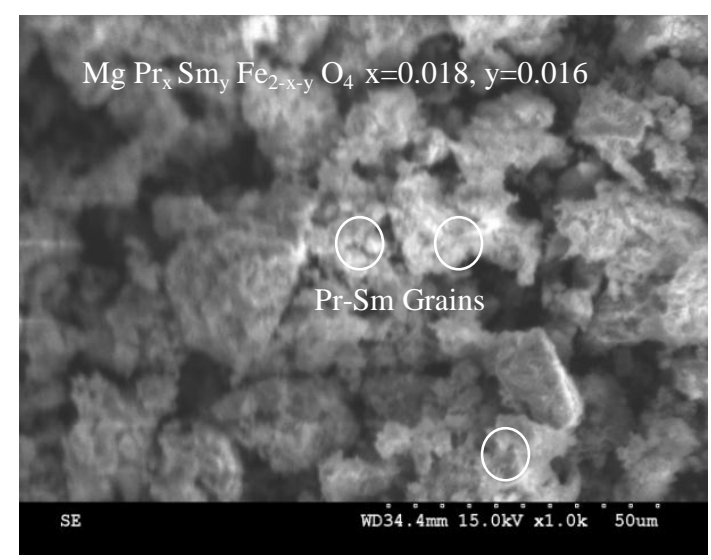

Fig.7 $\mathrm{MgPr}_{\mathrm{x}} \mathrm{Sm}_{\mathrm{y}} \mathrm{Fe}_{2-\mathrm{x}-\mathrm{y}} \mathrm{O}_{4} \mathrm{x}=0.09, \mathrm{y}=0.05$

\subsection{Hysteresis studies:}

Table 2 The change in magnetic saturation, retentivity, coercive force with changes in Pr-Sm doping concentration

\begin{tabular}{|c|c|c|c|c|c|c|c|c|}
\hline \multirow[t]{2}{*}{ S.N } & \multicolumn{2}{|c|}{$\begin{array}{c}\text { Material } \\
\mathrm{Mg} \mathrm{Pr}_{\mathrm{x}} \mathrm{Sm}_{\mathrm{y}} \mathrm{Fe}_{2-x-y} \mathrm{O}_{4}\end{array}$} & \multirow{2}{*}{$\begin{array}{c}\text { Coercivity } \\
\text { (G) }\end{array}$} & \multicolumn{2}{|c|}{$\begin{array}{l}\text { Remanance } \\
\text { (emu/g) }\end{array}$} & \multicolumn{2}{|c|}{$\begin{array}{c}\text { Saturation } \\
\text { Magnetization (emu/g) }\end{array}$} & \multirow{2}{*}{$\begin{array}{c}\text { Retentivity } \\
\text { (emu/g) }\end{array}$} \\
\hline & $x$ & $y$ & & Positive & Negative & Positive & Negative & \\
\hline 1 & 0.05 & 0.03 & 345.62 & 11.181 & -11.039 & 15.383 & -25.680 & 11.110 \\
\hline 2 & 0.06 & 0.03 & 349.61 & 6.4113 & -6.3726 & 25.673 & -15.350 & 6.3919 \\
\hline 3 & 0.08 & 0.04 & 346.79 & 13.809 & -13.719 & 31.517 & -31.506 & 13.764 \\
\hline
\end{tabular}

The different parameters such as saturation magnetization $\left(\mathrm{M}_{\mathrm{C}}\right)$, coercive force $\left(\mathrm{H}_{\mathrm{C}}\right)$, and Retentivity, The dielectric constant $\varepsilon_{\mathrm{r}}$ and dielectric loss $\varepsilon_{\mathrm{r}}{ }^{\prime}$ are listed in Table 3. The magnetic properties have been seen to be altered by the addition of $\mathrm{Pr}$ and $\mathrm{Sm}$ in $\mathrm{Mg}$ ferrite, It is observed that the saturation magnetization increases with the addition of $\mathrm{Pr}$ and $\mathrm{Sm}$. Rezlescu et al. [16], the saturation magnetization of $\operatorname{Pr}^{3+}$ and $\mathrm{Sm}^{3+}$ is substituted in Magnesium ferrites is higher than that of un substituted ferrite. Similar results are reported by Liu et al. [17] in $\mathrm{Pr}^{3+}$ and $\mathrm{Sm}^{3+}$ substituted M-type Cerium ferrite and similar results is reported by Gama et al is seen in cerium-doped $\mathrm{Zn}$ ferrite [18]. 
Fig.8 Magnetic hysteresis loop for Dy-Sm doped Mgferrite

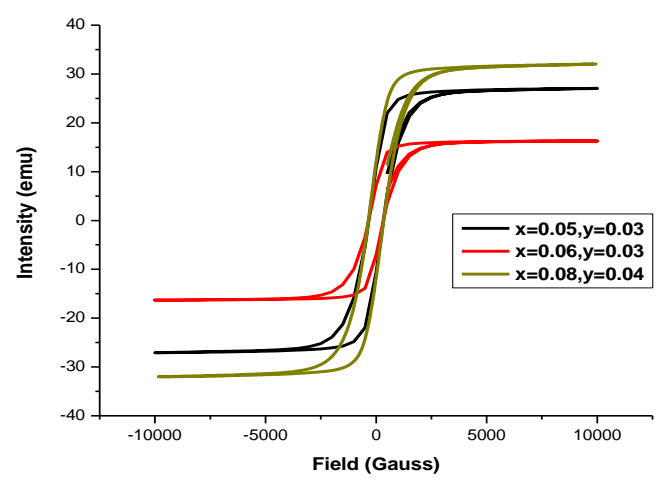

Therefore 3.8 is observed for the sample $\mathrm{Zn}_{0.978} \mathrm{Ce}_{0.012} \mathrm{Co}_{0.01}$ $\mathrm{Fe}_{2} \mathrm{O}_{4}$ and minimum is 0.645 for the sample $\mathrm{Zn}_{0.985} \mathrm{Ce}_{0.014} \mathrm{Co}_{0.001} \mathrm{Fe}_{2} \mathrm{O}_{4}$, as mentioned in table 3. These values are attributed to better concentration and nature of the ions in $\mathrm{A}$ and $\mathrm{B}$ site causes resultant magnetization to be different as reported.

The effect of grain size on initial permeability and found a linear relation between the initial permeability and grain size in Pr-Sm doped magnesium ferrite. The relationship between $\mu_{\mathrm{i}}$, saturation magnetization $\mathrm{M}_{\mathrm{s}}$ and grain size $\mathrm{D}$ can be expressed as $[19,20]$

$$
\mu_{\mathrm{i}}=\mathrm{M}_{\mathrm{s}}^{2} \mathrm{D} / \mathrm{K}_{1}
$$

where $\mathrm{Ms}$ is the saturation magnetization, $\mathrm{D}$ the average grain size and $\mathrm{K}_{1}$ is the magneto-crystalline anisotropy constant. The relation between $\mu_{\mathrm{i}}$ with Ms and D for the Pr doped nano ceramic magnesium ferrites show the agreement with the Eq.(5) relationship as shown in Fig 7(a) and 7(b), that is $\mu_{\mathrm{i}} \alpha \mathrm{Ms}$ and $\mu_{\mathrm{i}}$ $\alpha \mathrm{D}[21]$.

$$
\mathrm{K}_{1}=\frac{\mathrm{M}_{\mathrm{s}} \mathrm{H}_{\mathrm{c}}}{0.96}
$$

\subsection{Electrical Properties}

The dielectric constant $\varepsilon_{\mathrm{r}}$ and dielectric loss $\varepsilon_{\mathrm{r}}{ }^{\prime}$ of the sintered samples $\mathrm{Mg} \operatorname{Pr}_{\mathrm{x}} \mathrm{Sm}_{\mathrm{y}} \mathrm{Fe}_{2-\mathrm{x}-\mathrm{y}} \mathrm{O}_{4}$, over the microwave frequency range from $10 \mathrm{M}-20 \mathrm{GHz}$ are shown in figure 10 and 11 . The plots 11,12 show that the $\varepsilon_{\mathrm{r}}$ and $\varepsilon_{\mathrm{r}}{ }^{\prime}$ values tend to decrease exponentially, it is also seen that the value of $\varepsilon_{\mathrm{r}}$ and

study, The maximum value of dielectric constant compositional stoichiometry single phase spinal structure and uniform microstructure of the sample. The general trend for all composition is that $\dot{\varepsilon}$ and $\varepsilon^{\prime \prime}$ decrease with increasing frequency[22]. single phase spinal structure and uniform microstructure of the sample. The general trend for all composition is that $\varepsilon$ and $\varepsilon^{\prime \prime}$ decrease with increasing frequency.

This behavior of a dielectric may be explained qualitatively by the supposition that the mechanism

of the polarization process in ferrite is similar to that the conduction process. $\mathrm{e}_{2} \mathrm{O}_{4}$, as mentioned in table 3..These values are attributed to better compositional stoichiometry single phase spinal structure and uniform microstructure of the sample. The general trend for all composition is that $\dot{\varepsilon}$ and $\varepsilon^{\prime \prime}$ decrease with increasing frequency. This behavior of a dielectric may be explained qualitatively by the supposition that the mechanism of the polarization process in ferrite is similar to that the conduction process. The electrical conduction mechanism can be explained by the electron hopping model of Heikes and Johnston [23]. It is known that the effect of polarization is to reduce the field inside the medium. Therefore, the dielectric constant of a substance may be decreased substantially as the frequency is increased.

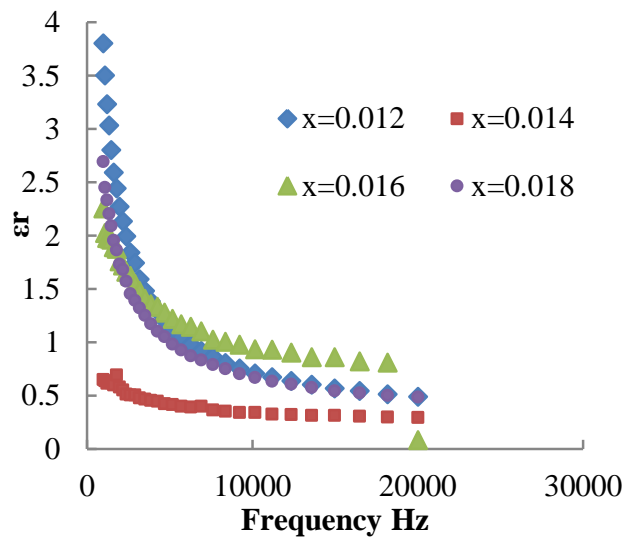

Fig9.Dielectric constant for $\mathrm{Mg} \mathrm{Pr}_{\mathrm{x}} \mathrm{Sm}_{\mathrm{y}} \mathrm{Fe}_{2-x-y} \mathrm{O}_{4}$

\section{CONCLUSION:}

The dielectric constant $\varepsilon_{\mathrm{r}}$ and the dielectric loss $\varepsilon_{\mathrm{r}}{ }^{\prime}$ decrease with increasing frequency for all Praseodymium, Samarium doped ferrites. This behavior of a dielectric is explained qualitatively in terms of the supposition that the process of dielectric polarization takes place through a mechanism similar to the conduction process. The increase in the electrical conductivity at

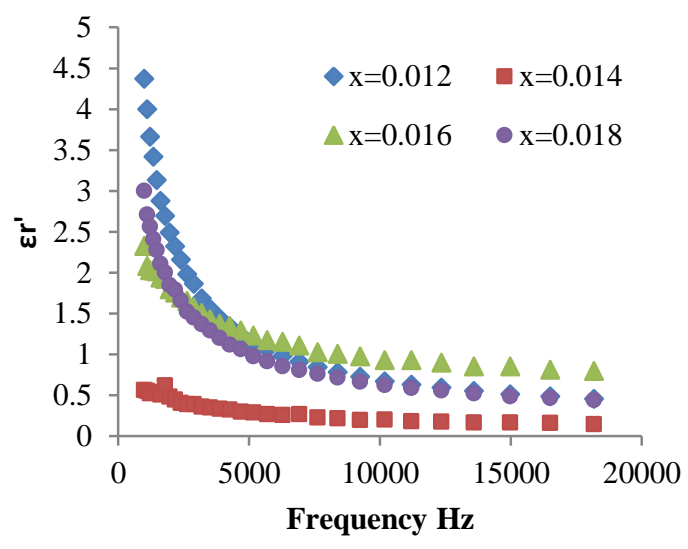

Fig 10. Dielectric loss for $\mathrm{Mg} \mathrm{Pr}_{x} \mathrm{Sm}_{y} \mathrm{Fe}_{2-x-y} \mathrm{O}_{4}$

low temperature is attributed to the impurities, which reside at the grain boundaries. It is seen that the value of $\varepsilon_{\mathrm{r}}$ and $\varepsilon_{\mathrm{r}}^{\prime}$ increases with the addition of $\mathrm{Pr}$ and $\mathrm{Sm}$ atom concentration, while the capacitance value remains fairly constant for this range of frequency. This investigation also indicates that the addition of Praseodymium and Samarium in zinc ferrite showed a small change in magnetic properties. It is expected that a large concentration of Praseodymium and Samarium may cause a 
significant structural change which in turn may enhance the magnetic properties [24-25].

\section{REFERENCES}

[1] Ü.Özgür, Y.Alivov, and H.Morkoç, "Microwave Ferrites, Part 1: Fundamental Properties", [J] J. Mater. Sci.: Materials in Electronics, 2009, 1-169.

[2] V..R.K.Murthy,B.Viswanathan, [M] Ferrite Materials, Narosa Publishing House,(1990).

[3] Wilhelm Van Aulock (Ed.), [M] Handbook of microwaves ferrites Materials ,Academic Press,Newyork,London,1965

[4] J.F Huheey. and E.A Keiter., [M] Chemistry Principles of Structure and Reactivity, College Publishers, Harper Collins, 1993.

[5] L.A Vermenko., T.Y Gridasova., and E.N Lukachina., The effect of addition of rare earth element oxides on the properties of nickel ferrite, Poroshk. Metall., 1973, 9 (129): 52.

[6] A.K.M.A Hossain, T. S Biswas, T Yanagida, H Tanaka, H Tabata, T Kawai, Investigation of Structural and Magnetic Properties of Polycrystalline $\mathrm{Ni}_{0.50} \mathrm{Zn}_{0.50-\mathrm{x}} \mathrm{Mg}_{\mathrm{x}} \mathrm{Fe}_{2} \mathrm{O}_{4}$ Materials, Chemistry and Physics, 120 (2010) $461-467$.

[7] Thant A. A., S. Srimala, P. Kaung, M. Itoh, O. Radzali1 and M. N. Ahmad Fauzi1, Low Temperature Synthesis of $\mathrm{MgFe}_{2} \mathrm{O}_{4}$ Soft Ferrite Nanocrystallites, Journal of the Australian Ceramic Society, 46[1] (2010) 11-14.

[8] A.Senthil Kumar, Synthesis of Nano sized Sm-Gd doped Magnesium ferrite and their Permittivity and Hysteresis Studies International Journal of Computer Applications Volume 30- No.7), September 2011, pp 13-23.

[9] Muthu Ramam, Synthesis of Nano sized Ce-Co Doped Zinc Ferrite and their Permittivity and Hysteresis Studies. International Journal of Computer Applications (0975 8887) Volume 32- No.3, October 2011, pp18- 27

[10] A. Pradeep, P .Priyadharsini, G.Chandrasekaran., Sol-gel route of nanoparticles of $\mathrm{MgFe}_{2} \mathrm{O}_{4}$ and XRD,FTIR and VSM study , [J] Journal of Magn. Mag.Mater, 2008, 320, 2779 .

[11] B.R Karche.,B.VKhasbardar., and Vaingankar A.S., X-ray, SEM and magnetic properties of $\mathrm{Mg}-\mathrm{Cd}$ ferrites, $[\mathrm{J}] \mathrm{J}$. Magn. Magn.Mater., 1997,168,292.

[12] L.B Kong., et.al, Magneto-Dielectric Properties of Mg-CuCo Ferrite Ceramics: II Electrical, Dielectric, and Magnetic Properties , [J] J. Am. Ceram. Soc., 2007, 7, 2104-2112.

[13] P.K. Roy, J. Bera, Enhancement of the magnetic properties of $\mathrm{Ni}-\mathrm{Cu}-\mathrm{Zn}$ ferrites with the substitution of a small fraction of lanthanum for iron, Materials Research Bulletin (2006)

[14] B.D Cullity., Elements of X-Ray Diffraction, Addison Wesley Pub. Co. Inc., London 1967: 96.

[15] A.A Sattar.., et.al, Rare Earth Doping Effect on the Electrical Properties of $\mathrm{Cu}-\mathrm{Zn}$ Ferrites, $[\mathrm{J}]$ J. Phys. IV France 1997, 7.

[16] N Rezlescu., ERezlescu., C Pasnicu., and M.L Craus., Effect of the rare-earth ions on some properties of nickelzinc ferrite, J. Phys. Condens. Matter, 1994, 6: 5707

[17] X Liu., W Zhong., S Yang., Z Yu., B Gu., and Y Du., Influence of $\mathrm{La}^{3+}$ substitution on the structural and magnetic properties of M-type strontium ferrites, J. Magn. Magn. Mater., 2002, 238 (2-3): 207

[18] M.Sheik Dawood,Magnetic Properties of Nano Crystalline Nickel, Samarium doped Zinc Ferrite, International Journal of Computer Applications Volume 24- No.2 (0975 - 8887), June 2011, pp18-22.

[19] M.Penchal Reddy, Structural ,Magnetic and electrical properties of $\mathrm{NiCuZn}$ ferrites prepared by microwave sintering method suitable for MLCI application, Journal of Physics and Chemistry of solids 71 (2010) 1373-1380.

[20] Vasant Naidu et.al, Magnetic property study of nickel cerium substituted zinc ferrite nano particles, International Journal of Computer Applications , 40[4] (2012) pp 7-12.

[21] R.G Kulkarni., H Joshi, Comparison of magnetic properties of $\mathrm{MgFe} 2 \mathrm{O} 4$ prepared by wet-chemical and ceramic methods, [J] Journal.Solid State Chem, 1986 ,64, 2, 141

[22] S.K.A Ahamed Kandu Sahib, Study of Electrical and Magnetic properties in Nano sized Ce-Gd Doped Magnesium Ferrite, International Journal of Computer Applications, International Journal of Computer Applications Volume 27- No.5 August 2011, pp 40-45.

[23] R. R. Heikes and D. Johnston, The Preparation and Magnetic Properties of High Purity Raney Iron J. Chem. Phys. 26, 582 (1957).

[24] E.Melagiriyappa, H.S Jayanna, B.K.Chougule., Dielectric behavior and ac electrical conductivity study of $\mathrm{Sm}^{3+}$ substituted Materials Chemistry and Physics, 2008 , 112, 68-73.

[25] S.S Jadhav, S.M Patange, K.M Jadhav, Dielectric behaviour study of nanocrystalline Co-Zn ferrite., Journal of Biomedical and Bioengineering, , Vol. 1, Issue 1, 2010, PP21-29. 